\title{
The Effects of Robot-Assisted Gait Training with Visual Feedback on Gait, Balance and Balance Confidence in Chronic Stroke Patients
}

\author{
Sin-Cheol Ham', Chae-Gil Lim² \\ 'Department of Graduate School of Public Health, College of Health Science, Gachon University; ${ }^{2}$ Department of Physical Therapy, College of \\ Health Science, Gachon University
}

Purpose: This study was conducted to assess the effects of robot-assisted gait training with visual feedback on gait, balance, and balance confidence in patients with chronic stroke.

Methods: Thirty subjects with chronic stroke were randomly assigned to two groups: the experimental group $(n=15)$ and the control group $(n=15)$. The experimental group performed robot-assisted gait training for 30 minutes and the control group performed gait training with assisted devices training for 30 minutes after both groups performed conventional physical therapy for 30 minutes. Both groups performed the therapeutic interventions for 5 days per week, for a period of 4 weeks. For assessment of the $10 \mathrm{~m}$ walking test (10 MWT), Figure of 8 on the walk test (F8WT), Timed-Up and Go test (TUG), and Berg Balance Scale (BBS) were used to test the gait and balance, and the Korean version of the Activities-specific Balance Confidence Scale was used to test the balance confidence.

Results: The experimental group showed significant improvement in the $10 \mathrm{MWT}$ and the K-ABC $(p<0.05)$, and the control group showed significant improvement in the BBS and the TUG $(p<0.05)$. In four measurements, there were significant differences between the two groups $(p<0.05)$, and the control group showed significant improvement in the F8WT at pre and post intervention $(p<0.05)$.

Conclusion: This study demonstrated that Robot-assisted gait training with visual feedback is an effective intervention for improving straight gait abilities and balance confidence, while the control group showed some improvement in curve gait and balance. Thus, we suggest both Robot-assisted gait training with visual feedback and gait training with assisted devices training exercise as a therapeutic intervention in chronic stroke rehabilitation.

Keywords: Robot-assisted gait, Stroke, Balance, Balance confidence

\section{서 론}

뇌졸중은 우리나라 사망원인 1 위의 순환기계 및 신경계 질환으로 평 균수명이 연장됨에 따라 발병률이 증가하고 있다. 뇌졸중이 발생하 면, 환자의 $20 \%$ 정도는 모든 것을 타인에게 의지해야 하는 상태가 되 며 70-75\%는 완전히 회복되지 못하고 심각성 정도에 따라 보행능력 및 균형능력의 저하, 감각의 손상 등의 문제를 동반한다. ${ }^{2}$

뇌졸중으로 인한 보행능력의 손상은 환자가 기능적 독립을 달성 하는 데 큰 장애 요소이며 환자의 일상생활의 제한을 가져오고, 삶의 질을 저하시킨다. 그러므로 환자의 재활에 있어서 보행능력의 획득 은 환자의 독립성과 직결되는 중요한 요소이며 치료사와 환자가 중요 하게 생각하는 치료의 목표가 된다. 일반적으로 뇌졸중 발병 후 운
동기능의 회복은 초기에 이루어지고, 발병 후 초기에 재활치료에 참 여하는 것은 운동기능의 회복을 촉진하는 데 도움이 된다. 또한, 전 통적으로 재활 프로그램들은 뇌졸중 후 초기 3 개월 기간에 집중되 어 있으며, 이 시기 이후, 손상 측의 운동기능이 회복되지 않으면, 환 자들은 일상적인 과제수행을 위해 정상 측 상지기능을 사용하면서 손상 측 운동기능을 보상하려는 행동이 일반적으로 나타나게 된다. ${ }^{5}$ 최근에는 환자를 급성, 아급성, 만성으로 분류하여 전통적인 재활프 로그램과 최신재활프로그램을 단계별로 적용하여, 6 개월이 지난 환 자에게 재활훈련의 효과를 검증하려는 노력이 진행되어왔고, 임상에 서 활용 중에 있다. ${ }^{6}$

최근 뇌졸중 환자의 보행능력 향상을 위한 다양한 방법 중에는 시 각적 되먹임 훈련 및 청각적 되먹임 훈련을 이용한 감각운동훈련 등
Received Mar 22, 2016 Revised Apr 18, 2016

Accepted Apr 18, 2016

Corresponding author Chae-Gil Lim

E-mail jgyim@gachon.ac.kr
Copylight (C2016 The Korea Society of Physical Therapy

This is an Open Access article distribute under the terms of the Creative Commons Attribution Non-commercial License (Http:// creativecommons.org/license/by-nc/3.0.) which permits unrestricted non-commercial use, distribution, and reproduction in any medium, provided the original work is properly cited. 
이 있으며, 특히 시각적 되먹임을 이용한 훈련은 환자의 움직임에 대 한 오류를 정확하고 빠르게 시각의 정보로 받아 이를 수정함으로써 운동학습을 촉진시키는 데 도움이 되며, 이러한 시각적 되먹임 훈련 이 뇌졸중 환자의 보행능력을 향상시킨다고 하였다. 시각적 되먹임 로봇-보조 보행훈련은 전방의 스크린에 가상현실 시스템을 사용하 고 있고, 적절한 동기부여를 이끌어 낼 수 있다. ${ }^{8}$ 또한 환자는 적절한 강도에서 양측 다리를 능동적으로 움직일 수 있도록 하여 치료과정 에서 문제를 해결해가면서 움직임을 학습하는 것이 효과적이라는 운동학습이론에 기초를 두고 있다. ${ }^{9}$

그러나 시각적 되먹임 훈련이 뇌졸중 환자의 손상 측에 체중 지지 를 향상시키고 기립자세의 안정성을 높이는 것으로 알려져 있고, ${ }^{10}$ 발 병 초기 뇌졸중 환자의 보행치료의 효과는 다양하게 연구되고 있지 만, ${ }^{3}$ 기능회복이 정점에 이르고 만성기에 접어든 뇌졸중 환자의 보행, 균형, 균형자신감을 향상시키기 위한 치료전략에 관한 연구는 부족 하다. 따라서 본 연구는 만성뇌졸중 환자에게 시각적 되먹임 로봇-보 조 보행훈련을 실시하고 대조군과 치료 전. 후의 보행, 균형, 균형자신 감에 대한 효과를 알아보고자 하였다.

\section{연구방법}

\section{1. 연구대상}

본 연구의 대상은 2015년 1월부터 6월까지 인천광역시 소재 M재활 병원에 입원한 환자 중 연구 참여에 동의하고 동의서를 작성한 40 명 의 환자 중 퇴원과 기타 이유로 탈락한 10 명을 제외하고 요건을 충족 한 30 명으로 선정하였다.

1) 40 세 이상 70 세 이하, 뇌졸중진단으로 편마비 증상이 있은 지 6 개월 이상

2) 발병 이전 특별한 외과적 손상이나 질환이 없는 자

3) 선천적으로 고관절, 슬관절, 족관절의 기형이 없는 자

4) 기타보조기구의 착용유무에 관계없이 $10 \mathrm{~m}$ 이상 보행 가능한자

5) 시각, 청각, 전정감각에 이상이 없는 자

6) 연구의 지시 내용을 이해할 수 있는 의식 수준이 명료한 자 (MMSE-K 24점 이상)

\section{2. 실험방법}

\section{1) 실험 절차}

본 연구는 30 명의 만성뇌졸중 환자를 실험군과 대조군으로 각각 15 명씩 무작위로 배정하였다. 실험군은 시각적 되먹임 로봇-보조 보 행훈련을 회당 30 분, 주 5 회, 4 주간 시행하였다. 또한 추가적으로 일반 적인 운동치료를 회당 30 분, 주 5 회, 4 주 동안 시행하였다. 반면 대조 군은 보조 및 보조도구를 이용한 보행훈련으로 평행봉 걷기, 보조도
구 이용한 걷기로 30 분, 일반적인 운동치료는 30 분간 실험군과 동일 하게 적용하였다. 4 주간의 중재 후 동일한 측정자에 의하여 사후 평 가를 시행하였다.

실험군은 Lokomat ${ }^{\circledR}$ (Hocoma AG, Zurich, Switzerland)을 사용하여 보행훈련을 받았다. Lokomat ${ }^{\circledR}$ 은 자세제어용 로봇 보행 보조장치와 체중 부하 장치로 되어있으며 Woodway treadmill (Weil am Rhenin, Germany)과 연동하여 작동된다. 시각적 되먹임 로봇-보조 보행훈련 은 다음과 같다. 체중 부하 장치에 부착된 하네스(harness)를 착용하 여 서 있게 한 뒤 환자의 다리를 엉덩관절, 무릎관절, 발목관절 순으 로 Lokomat ${ }^{\circledR}$ 과 결합시킨다. 엉덩관절, 무릎관절의 각도와 힘의 조절 은 각 관절에 내장된 센서를 통해 조절이 가능하며 트레드밀의 속도 와 체중 지지도 조절이 가능하다. 속도는 환자가 치료시간 동안 수행 할 수 있는 최대의 속도로 진행하였으며, 토크의 조절과 체중 지지 강 도를 환자가 치료시간 동안 수행할 수 있을 정도로 지지 비율을 감소 시켰다. 로봇-보조 보행 훈련 시 전방에 스크린은 가상현실 시스템을 사용하였고, 가상현실 시스템은 Lokomat ${ }^{\circledR}$ 를 사용하는 동안 시각적 되먹임을 제공한다. 시각적 되먹임은 환자와 Lokomat ${ }^{\circledR}$ 의 상호적인 힘의 정도를 센서에서 반응하여 이를 가상현실 시스템의 아바타에 보여주어 시각적 되먹임을 제공한다. 이는 환자가 가상현실에서 보이 는 환경에서 나타는 반응을 다시 Lokomat ${ }^{\circledR}$ 의 센서가 반응함으로써 상호적인 영향을 받는다. 본 연구에서 사용된 프로그램은 주어진 시 간 동안 가상현실의 숲속을 보행하면서 장애물을 피하며 동물을 잡 는 프로그램으로 동물을 잡을 경우 점수를 획득하는 방식으로 환자 의 반응 및 동기부여를 끌어낼 수 있도록 하였다.

균형 능력을 측정하기 위하여 Berg Balance Scale (BBS) 검사, 균형자 신감검사를 위해 Korean version of Activities-specific Balance Confidence Scale (K-ABC)를 시행하였으며, 보행 능력은 $10 \mathrm{~m}$ walking test (10 MWT), Figure of 8 walk test (F8WT) 와 Timed-Up and Go test (TUG) 검 사를 이용하였다. 모든 측정을 3 회 실시하여 평균값을 구하였다. 측 정 오차를 최소화하기 위하여 전후 동일한 측정자가 동일한 장소에 서 평가를 실시하였고, 모두 맹검된 상태에서 시행하였다.

\section{2) 측정도구}

\section{(1) Berg balance scale}

$\mathrm{BBS}$ 검사는 뇌졸중 환자의 낙상 위험도 및 동적 균형을 측정하기 위하여 사용되는 임상측정 방법이다. ${ }^{11}$ 본 측정은 총 14 개의 항목으 로 구성되어 있다. 자세변화, 서기, 앉기의 3 개의 대 하위영역으로 구 분되고 최소 0 점, 최고 4 점으로 총 14 개 항목에 대한 총 56 점 만점으 로 구성된다. BBS 검사는 뇌졸중 환자에서 측정자 내 신뢰도가 $r=0.97$ 이고, 검사-재검사 신뢰도가 $r=0.98$ 에 해당하는, 매우 높은 신 뢰도가 보고되었다. ${ }^{12}$ 
(2) Korean version of Activities-specific Balance Confidence Scale

뇌졸중 환자의 균형자신감 측정을 위해 개발된 척도 ${ }^{13}$ 를 우리나라 의 실정에 맞게 수정 보완한 한국어판 활동 특이적 균형 자신감 척도 라는 도구를 사용하였다. ${ }^{14}$ 이 도구는 총 16 항목으로 구성되며 각 문 항은 “전혀 자신 없다" 0에서부터 "완전 자신 있다" 100으로 되어있어 자가 보고식으로 측정하며, 16 개의 일상생활 활동에 대한 균형자신 점수를 합산하여 평균을 산출하였다. 점수는 0 점에서 100 점으로 점 수가 높을수록 균형에 대한 자신감이 높은 것을 의미한다. 한국어판 활동 특이적 균형자신감 척도의 타당도는 $\mathrm{p}=0.0019$ 및 신뢰도는 $a$ $=0.96$ 이다.

\section{(3) $10 \mathrm{~m}$ walking test}

$10 \mathrm{MWT}$ 는 직선 보행 능력을 평가하기 위한 검사이다. ${ }^{15}$ 총 $14 \mathrm{~m}$ 를 최고 속도로 걷게 하고 처음 $2 \mathrm{~m}$ 와 마지막 $2 \mathrm{~m}$ 는 측정에서 제외하였 다. 보행속도 단위는 초(sec)이고 대상자가 한번 걷게 하여 적응하도록 한 후 3 회 실시하여 각각의 평균값을 사용하였다. 이 측정도구는 측 정자 내 신뢰도, 측정자 간 신뢰도 $r=0.87$ 이다. ${ }^{15}$ 총 대상자들에게 한 번의 연습시도가 주어졌고 본 측정을 시행하였다. 각 측정 사이는 근 육의 피로 유발을 방지하기 위하여 1 분 동안 휴식을 취하게 하였다. ${ }^{16}$

\section{(4) Figure of 8 walk test}

F8WT 검사는 곡선 보행 능력을 평가하기 위한 검사이다. ${ }^{17} \mathrm{~F} 8 \mathrm{WT}$ 의 측정방법은 약 $1.5 \mathrm{~m}$ 거리를 두고 양쪽에 각 한 개씩 원뿔을 설치 한다. 원뿔 사이 중앙에 시작점을 표시하고 곡선 주행 방향을 선택하 게 한 후 원뿔면으로부터 바깥쪽으로 향해 서게 하여 준비가 되면 걷 게 한다. 그리고 시작점으로 돌아오면 된다. 완주한 거리에 대한 보행 시간을 3 회 측정하였고, 그 평균값을 사용하였다. 이 측정도구는 측 정자 내 신뢰도 $r=0.84$, 측정자 간 신뢰도 $r=0.92$ 이다. ${ }^{17}$

\section{(5) Timed-Up and Go test}

TUG 검사는 뇌졸중 환자에서 보행 및 동적 균형능력을 측정 시 사용되는 검사방법으로서, 측정이 간단하고 신속하다..$^{18}$ 의자에서 일 어나 $3 \mathrm{~m}$ 전방을 걸어가기, 돌기, 걸어서 돌아오기, 의자에 앉기 순으 로 진행되며, 이와 같은 일련의 동작을 수행하는 데 소요되는 시간을 기록하여 측정한다. 본 검사는 95 이상의 신뢰도가 높은 측정방법으 로, ${ }^{19}$ 본 연구에서는 뇌졸중 환자의 보행능력을 측정하기 위하여 사 용되었다.

\section{3. 자료분석 및 통계 방법}

본 실험의 자료는 SPSS Version 18.0 (IBM, Somers, NY, USA)을 이용 하여 측정치의 평균 및 표준편차를 구하였다. 모든 대상자는 Shapiro-
Wilk 검정방법을 사용하여 정규성 검정을 시행하였다. 대상자의 일 반적인 특성은 카이검정과 독립표본 $\mathrm{t}$ 검정을 사용하여 비교하였다. 각 집단 내의 중재 전후를 비교하기 위하여 대응표본 $\mathrm{t}$ 검정을 실시하 였고, 집단 간의 차이를 분석하기 위하여 독립표본 $\mathrm{t}$ 검정을 실시하였 다. 모든 결과는 평균과 표준편차를 표시하였으며, 모든 통계적 유의 검증수준은 0.05 이하로 하였다.

\section{결 과}

\section{1. 연구대상자의 일반적 특성}

본 연구에 참가한 대상자의 일반적 특성은 Table 1과 같다. 두 그룹 간의 성별, 연령, 신장, 체중, 유병기간 및 인지기능에서 유의한 차이는 없었다 $(\mathrm{p}>0.05)$.

\section{2. 균형 능력과 균형자신감 변화}

본 연구는 균형 능력을 측정하기 위하여 BBS 검사를 수행하였고 다음과 같은 결과를 얻었다. BBS 검사는 시각적 되먹임 로봇-보조 보 행훈련을 한 실험군에서 중재 전 39.00점에서 중재 후 39.60점으로 유 의한 차이가 없었으며 $(\mathrm{p}>0.05)$, 보조 및 보조도구를 이용한 보행훈련 을 한 대조군에서는 중재 전 40.47 점에서 중재 후 42.80 점으로 유의한 증가를 보였다 $(\mathrm{p}<0.05)$. 또한 대조군은 실험군에 비하여 통계적으로 유의한 BBS 개선을 보였다 $(\mathrm{p}<0.05)$ (Table 2$)$.

$\mathrm{BBS}$ 검사와는 다르게, $\mathrm{K}-\mathrm{ABC}$ 검사에서는 실험군에서 중재 전 620.00점에서 중재 후 768.00점으로 유의한 향상을 보였으며 $(\mathrm{p}<0.05)$, 대조군에서는 중재 전 781.33점에서 중재 후 783.33점으로 유의하지 않았다 $(\mathrm{p}>0.05)$. 실험군은 대조군에 비하여 통계적으로 유의한 개선 을 나타냈다 $(\mathrm{p}<0.05)($ Table 2$)$

\section{3. 보행능력의 변화}

뇌졸중 환자의 직선보행과 곡선보행능력을 측정하기 위해 10 MWT, F8WT 와 TUG 검사를 시행하였고 다음과 같은 결과를 얻었다. 10 MWT에서 실험군은 중재 전 28.01초에서 중재 후 20.20초로 유

Table 1. General characteristics of subjects

\begin{tabular}{lccc}
\hline & $\begin{array}{c}\text { Experimental group } \\
(\mathrm{n}=15)\end{array}$ & $\begin{array}{c}\text { Control group } \\
(\mathrm{n}=15)\end{array}$ & $\mathrm{p}$ \\
\hline Gender (male/female) & $7 / 8$ & $8 / 7$ & 0.715 \\
Age (year) & $53.66 \pm 8.41$ & $58.77 \pm 9.93$ & 0.143 \\
Height (cm) & $163.26 \pm 8.58$ & $161.13 \pm 10.30$ & 0.415 \\
Weight (kg) & $64.66 \pm 10.16$ & $69.33 \pm 9.89$ & 0.213 \\
$\begin{array}{l}\text { Duration from Onset } \\
\text { (month) }\end{array}$ & $19.60 \pm 9.99$ & $15.60 \pm 6.89$ & 0.213 \\
MMSE-K & $26.40 \pm 2.77$ & $25.53 \pm 2.29$ & 0.359 \\
\hline
\end{tabular}

Values are expressed as mean \pm standard deviation. 
Table 2. The changes of the balance, the balance confidence and the gait abilities

\begin{tabular}{|c|c|c|c|c|c|}
\hline & & Experimental group & Control group & $\mathrm{t}$ & $p$ \\
\hline \multirow[t]{5}{*}{ BBS (score) } & Pretest & $39.00 \pm 6.14$ & $40.47 \pm 6.81$ & & \\
\hline & Posttest & $39.60 \pm 5.19$ & $42.80 \pm 6.73$ & & \\
\hline & Post - Pre & $0.6 \pm 2.26$ & $2.33 \pm 2.12$ & 2.162 & $0.039^{*}$ \\
\hline & $\mathrm{t}$ & 1.028 & 4.249 & & \\
\hline & $\mathrm{p}$ & 0.322 & $0.010^{+}$ & & \\
\hline \multirow[t]{5}{*}{ K-ABC (score) } & Pretest & $620.00 \pm 359.56$ & $781.33 \pm 337.255$ & & \\
\hline & Posttest & $768.00 \pm 283.25$ & $783.33 \pm 333.202$ & & \\
\hline & Post - Pre & $140.00 \pm 227.41$ & $2.00 \pm 99.87$ & 2.277 & $0.034^{*}$ \\
\hline & $\mathrm{t}$ & 2.521 & 0.078 & & \\
\hline & $\mathrm{p}$ & $0.024^{+}$ & 0.930 & & \\
\hline \multirow[t]{5}{*}{$10 \mathrm{MWT}$ (sec) } & Pretest & $28.01 \pm 13.15$ & $17.56 \pm 11.96$ & & \\
\hline & Posttest & $20.20 \pm 10.36$ & $16.30 \pm 9.51$ & & \\
\hline & Post - Pre & $7.81 \pm 6.69$ & $1.26 \pm 3.08$ & 3.438 & $0.003^{*}$ \\
\hline & $\mathrm{t}$ & 4.516 & 1.585 & & \\
\hline & $\mathrm{p}$ & $0.000^{+}$ & 0.135 & & \\
\hline \multirow[t]{5}{*}{ F8WT (sec) } & Pretest & $27.86 \pm 12.78$ & $20.57 \pm 9.25$ & & \\
\hline & Posttest & $25.79 \pm 14.18$ & $16.86 \pm 9.40$ & & \\
\hline & Post - Pre & $2.07 \pm 4.53$ & $3.70 \pm 3.09$ & 1.151 & 0.259 \\
\hline & $\mathrm{t}$ & 1.768 & 4.640 & & \\
\hline & $\mathrm{p}$ & 0.990 & $0.000^{+}$ & & \\
\hline \multirow[t]{5}{*}{ TUG (sec) } & Pretest & $24.19 \pm 10.41$ & $19.89 \pm 8.14$ & & \\
\hline & Posttest & $23.18 \pm 9.80$ & $16.91 \pm 6.68$ & & \\
\hline & Post - Pre & $1.01 \pm 1.54$ & $2.98 \pm 2.11$ & 2.914 & $0.007^{*}$ \\
\hline & $\mathrm{t}$ & 2.530 & 5.461 & & \\
\hline & $\mathrm{p}$ & $0.024^{+}$ & $0.000^{+}$ & & \\
\hline
\end{tabular}

Values are expressed as mean \pm standard deviation

BBS: Berg balance scale, K-ABC: Korean version of activities-specific balance confidence scale, 10 MWT: 10 m walking test, F8WT: figure of 8 walk test, TUG: timed-up and go test.

*Means a significant difference compared to the experimental group or the control group; 'Indicates a significant difference compared with pretest value.

의한 보행 능력의 개선을 나타낸 반면( $\mathrm{p}<0.05)$, 대조군은 중재 전 17.56 초에서 중재 후 16.30 초로 유의한 개선을 나타내지 못하였다 ( $\mathrm{p}>0.05)$. 실험군은 대조군에 비하여 통계적으로 유의한 $10 \mathrm{MWT}$ 의 개선을 나타냈다 $(\mathrm{p}<0.05)$ (Table 2).

F8WT에서 실험군은 중재 전 27.86초에서 중재 후 25.79초로 유의 한 감소가 없었던 반면(p>0.05), 대조군은 중재 전 20.57초에서 중재 후 16.86 초로 유의한 감소를 보였다 $(\mathrm{p}<0.05)$. 실험군과 대조군이 통계 적으로 유의한 차이는 없었다 $(\mathrm{p}>0.05)$ (Table 2).

TUG에서 실험군은 중재 전 24.19초에서 중재 후 23.18 초로 유의한 감소를 보였고 $(\mathrm{p}<0.05)$, 대조군도 중재 전 19.89 초에서 중재 후 16.91 초로 유의한 감소를 보였다 $(\mathrm{p}<0.05)$. 대조군은 실험군에 비하여 통계 적으로 유의한 TUG의 개선을 나타냈다 $(\mathrm{p}<0.05)$ (Table 2).

\section{고 찰}

본 연구는 만성 뇌졸중 환자를 대상으로 시각적 되먹임 로봇-보조
보행훈련이 균형 능력과 균형자신감 그리고 보행 능력의 개선이 미치 는 효과를 규명하기 위하여 시행되었으며, 다음과 같은 결과를 입증 하였다. 첫째, 시각적 되먹임 로봇-보조 보행훈련은 뇌졸중 편마비 환 자의 직선보행능력과 균형자신감을 유의하게 개선시켰다. 둘째, 보조 및 보조도구를 이용한 보행훈련은 뇌졸중 환자의 균형능력과 곡선 보행능력을 효과적으로 향상시켰다.

균형능력의 평가항목으로, 만성 뇌졸중 환자에게 보조 및 보조도 구를 이용한 보행훈련은 BBS 검사에서 약 $6 \%$ 의 균형 능력을 향상시 킨 반면, 시각적 되먹임 로봇-보조 보행훈련은 BBS 검사에서 약 $2 \%$ 의 유의하지 않은 증가를 나타냈다. 이를 통하여 만성 뇌졸중 환자에게 보조 및 보조도구를 이용한 보행훈련은 균형 기능을 효과적으로 증 진시킬 수 있음을 유추할 수 있다. 앞선 연구에서는 균형능력과 체간 안정성에 대하여 언급을 하고 있는데 체간 조절능력의 향상은 체간 의 안정성을 확보하여 균형능력에 많은 도움을 준다고 하였다. ${ }^{20,21}$ 임 상현장에서는 이미 환자가 보행하는 동안 손으로 보조하여 보행하거 나, 트레드밀에서 치료사가 보조하여 훈련하는 방법, 트레드밀에서 
체중을 부분적으로 지지한 채 치료사가 보조하는 방법들이 사용되 어 왔고, 오랜시간 치료사가 지속적으로 보조하여 과도한 신체노동 이 요구되어 문제적으로 제시되어 왔지만 보행능력이 향상되었다고 보고하였다.22 본 연구의 실험군에서는 환자에게 제공되는 체중 부하 장치로 인하여 환자 스스로의 체간의 안정성 확보 없이도 반복적인 보행훈련이 가능하도록 되어 있었지만, 대조군에서는 보행 훈련 시 치료사의 도움에 의한 환자 스스로의 체간 조절이 경험되었을 것이 다. 이러한 대조군의 체간 조절 경험은 뇌졸중 환자들의 체간 조절 능 력에 향상을 가져왔고 이를 통해 기능적인 균형능력을 평가하는 BBS 에서 차이가 있었을 것으로 사료된다. 따라서 본 연구에서의 시각적 되먹임 로봇-보조 보행훈련에서는 환자의 균형에 유의한 차이가 없 었던 것으로 생각된다. 따라서 임상에서 만성 뇌졸중 환자의 균형 기 능 재활 훈련에서 치료사의 보조나 보조기구를 이용한 훈련과 로봇보조 보행훈련과 적절하게 교대로 사용한다면 효과적인 균형 향상 을 가져올 것으로 사료된다.

직선보행과 곡선보행에 대한 평가결과 $10 \mathrm{MWT}$ 는 실험군이 약 $28 \%$ 의 유의한 향상을 나타낸 반면, 대조군은 약 $7 \%$ 의 유의하지 않은 향상을 보였다. TUG는 실험군과 대조군에서 각각 약 $4 \%$ 와 $15 \%$ 로 유 의한 감소를 보였으며, 대조군이 실험군보다 유의하게 향상되었다. F8WT에서는 실험군에서 약 7\%의 향상이 있었으나 중재 전후 유의 한 차이가 없었고, 대조군에서 약 $18 \%$ 의 유의한 향상이 있었으며, 대 조군이 실험군보다 유의하게 개선되었다. 본 연구에서 사용된 Lo$\mathrm{komat}^{\circledR}$ 은 자세제어용 로봇 보행 보조장치와 체중 부하 장치로 구성 되어있으며 Woodway treadmill (Weil am Rhenin, Germany)과 연동하 여 작동되며 정상 보행 양식을 모방하여 안전하고 반복적인 직선보 행 훈련을 수행하는 장비이다. ${ }^{23}$ 하지만 실제 삶과 연루되어 있는 일 상생활 동작에서는 단순한 직선보행만을 하지 않는다고 하였다. ${ }^{24}$ 또 한 원하는 곳으로 이동하기 위해서는 다양한 방향의 곡선으로 회전 하며 걷는 것은 166 도에서 210 도 범위 사이를 사용한다. 본 연구에는 직선보행능력의 평가를 위해서 $10 \mathrm{MWT}$ 와 TUG를 사용하였다. TUG 검사가 곡선 보행을 포함하고 있지만, 단 한 번의 회전과 같은 방향으 로의 회전만 포함되어 있고, 그 회전 또한 간단한 회전에 불과하다. ${ }^{25}$ ${ }^{27}$ 그러나 F8WT검사는 시계방향과 시계반대방향의 2 개의 곡선으로 구성되어 있다.17 따라서 곡선보행능력을 평가하는 데 사용되었고, 두 군에서의 차이는 없었지만, 치료사의 보조 및 보조도구를 이용한 중 재가 실험전후 유의한 차이를 보였다. 이전 연구에서 시각장애인 16 명을 대상으로 트레드밀을 통한 보행훈련이 직선보행에 도움을 준다 고 하였고, ${ }^{28}$ 또 다른 연구에서도 아급성기 뇌졸중 환자들이 트레드 밀을 통한 보행훈련 후 $10 \mathrm{MWT}$ 에서 유의한 차이가 있었다. ${ }^{29}$ 따라서 본 연구에서의 시각적 되먹임 로봇-보조 보행훈련은 만성뇌졸중 환 자의 직선보행에 도움이 될 것으로 생각된다.
균형자신감에 대한 평가결과 실험군에서 약 $23 \%$ 로 유의하게 향상 되었고, 대조군에서는 $0.2 \%$ 의 유의하지 않은 차이를 보였다. 실험군 이 대조군에 비해 통계적으로 유의한 향상을 나타내었다. 시각은 뇌 졸중 환자에게 신체상(body image)을 형성하게 하는 데 중요한 역할 을 하는데, ${ }^{30}$ 이러한 시각적 정보는 중추신경계에서 통합하여 시각 인지가 완성되며 다른 영역과 서로 상호 협력하여 운동을 조절하게 된다. ${ }^{31}$ 이전 연구에서도 시각적 바이오피드백 훈련은 시각적 되먹임 을 제공하므로 훈련 중에도 운동을 수행하는 대상자들이 실시간으 로 자신의 움직임을 평가할 수 있어 균형자신감에 유의한 차이를 보 였다. ${ }^{32}$ 또한 뇌졸중 환자에게 실제 영상흐름을 통한 트레드밀 훈련에 관한 연구에서 시각적 피드백을 제공한 실험군에서 균형자신감에 유의한 차이를 보였다. ${ }^{33}$ 따라서 본 연구에서의 시각적 되먹임 로봇보조 보행훈련이 만성뇌졸중 환자의 균형자신감에 도움이 될 것으 로 사료된다.

본 연구는 다음과 같은 제한점이 있다. 첫째, 편마비 환자 30 명을 대상으로 측정하였으나, 대상수가 부족하기 때문에 치료의 명확한 효과를 규명하기 위해서는 추후 연구를 통한 검증이 필요하다. 둘째, 대상자의 연령대가 40-70대로 한정되었기 때문에, 기타 연령대 및 연 령간 효과는 불분명하다. 셋째, 중재는 4 주만 적용하였기 때문에 운 동 기간에 의한 명확한 효과 규명은 불분명하며, 기타 운동 강도 및 운동 시점, 중재 횟수(session)에 대한 치료적 운동 규례의 최적화는 불분명하다. 따라서 추후에는 이를 규명하는 연구를 시행해야 할 것 이다.

본 연구결과를 통하여 시각적 되먹임 로봇-보조 보행훈련이 만성 뇌졸중 환자의 직선보행능력과 균형자신감의 개선에 효과적임을 증 명하였고, 또한 치료사의 보조나 보조기구를 통한 보행훈련이 균형 과 곡선보행에 더 효과적임을 보았다. 이를 통하여 임상에서 치료사 의 보조와 시각적 되먹임 로봇-보조 보행훈련을 적절하게 혼합하여 적용한다면 다양한 균형과 보행 능력 개선에 타당한 방법임을 알 수 있었다. 또한 추후 연구에서는 두 방법의 혼합운동프로그램이 더욱 효과적인지 규명해야 할 것이다.

\section{REFERENCES}

1. Statistics Korea. Annual report on the cause of death statistics, Seoul: Statistics Korea. 2012.

2. Monahan FD, Phipps WJ Phipps' Medical-Surgical Nursing Health \& Illness Perspectives. 8th ed. Missouri: Elsevier Mosby. 2007;1428-29.

3. Werner C, Von Frankenberg S, TreigT et al. Treadmill training with partial body weight support and an electromechanical gait trainer for restoration of gait in subacute stroke patients: A randomized cross over study. Stroke. 2002;33(12):2895-901.

4. Teasell RW, Foley NC, Bhogal SK et al. An evidence-based review of 
stroke rehabilitation. Top Stroke Rehabil. 2003;10(1):29-58.

5. TauE. Harnessing brain plasticity through behavioral techniques to produce new treatments in neurorehabilitation. American Psychologist. 2004:59:692-704.

6. Chen JC., Shaw FZ. Progress in sensorimotor rehabilitative physical therapy programs for stroke patients. World J Clin Cases.2014;2(8):316-26.

7. Seo DK, Oh DW, Lee SH. Effectiveness of ankle visuoperceptual feedback training on balance and gait functions in hemiparetic patients. J Kor Phys Ther. 2010;22(4):35-41.

8. Weiss PL, Rand D, Katz N. Video capture virtual reality as a flexible and effective rehabilitation tool. J Neuroeng Rehabil. 2004;1(1):1-12.

9. Shumway-Cook A, Woollacott MH. Motor control: translating research into clinical practice. 3rd ed. Philadelphia: Lippincott Williams \& Wilkins. 2007;3-83.

10. Walker C, Brouwer BJ, Culham EG. Use of visual feedback in retraining balance following acute stroke. Phys Ther. 2000;80(9):886-95.

11. Berg K, Wood-Dauphin S, Williams JI. The Balance Scale: Reliability assessment with elderly residents and patients with an acute stroke. Scand J Rehabil Med. 1995;27(1):27-36.

12. Blum L, Korner-Bitensky N. Usefulness of the Berg Balance Scale in stroke rehabilitation: a systematic review. Phys Ther. 2008;88(5):559-66.

13. Powell LE, Myers AM. The Activities-specific Confidence (ABC) Scale J Gerontol A Biol Sci Med Sci. 1995;50(1):M28-M34.

14. Jang SN, Cho SI, Ou SW et al. The Validity and Reliability of Korean Fall Efficacy Scale(FES) and Activities-specific Balance Confidence Scale(ABC). J Korean Geriatr Soc. 2003;7(4): 255-68.

15. Dean CM, Richards CL, Malouin F. Walking speed over 10metres overestimates locomotor capacity after stroke. Clin Rehabil. 2001;15(4): 41521.

16. Green J, Forster A, Young J. Reliability of gait speed measured by a timed walking test in patients one year after stroke. Clin Rehabil. 2002; 16(3):306-14.

17. Hess RJ, Brach JS, Piva SR et al. Walking Skill Can Be Assessed in Older Adults: Validity of the Figure-of-8 Walk Test. Phys Ther. 2010;90(1):8999.

18. Podsiadlo D, Richardson S. The timed "Up \& Go": A test of basic functional mobility for frail elderly persons. J Am Geriatr Soc. 1991;39(2):1428.

19. Ng SS, Hui-Chan CW. The timed up \& go test: Its reliability and association with lower-limb impairments and locomotor capacities in people with chronic stroke. Arch Phys Med Rehabil. 2005;86(8):1641-7.

20. Song BK. The Effect of Somatosensory Training on Postural Alignment and Trunk Control with Impairment of Visual Perception and Somato- sensary in stroke, Korea Association occupational Therapy Policy. 2011; 3(1):1-12.

21. Kim JY, Woo JH, Woo YK. The effect of virtual Horse-riding therapy on trunk control ability, balance and gait ability of stroke patients. J Korean Acad Ther. 2014;6(1):12-20.

22. Hornby TG, Campbell DD, Kahn JH. et al. Enhanced gait-related improvements after therapist versus robotic-assisted locomotor training in subjects with chronic stroke: A randomized controlled study. Stroke. 2008;39(6):1786-92.

23. Colombo G, Wirz M, Dietz V. Driven gait orthosis for improvement of locomotor training in paraplegic patients. Spinal Cord. 2001;39(5):2525.

24. Dite W, Temple VA. Development of a clinical measure of turning for older adults. Am J Phys Med Rehabil. 2002;81(11):857-66.

25. Podsiadlo D, Richardson S. The timed “ Up \& Go": A test of basic functional mobility for frail elderly persons. J Am Geriatr Soc. 1991;39(2):1428.

26. Wolf SL, Catlin PA, Gage K et al. Establishing the reliability and validity of measurements of walking time using the Emory Functional Ambulation Profile. Phys Ther. 1999;79(12):1122-33.

27. Jonsdottir J, Cattaneo D. Reliability and validity of the dynamic gait index in persons with chronic stroke. Arch Phys Med Rehabil. 2007;88(11): 1410-5.

28. Kim YD, Lee IK. The Effects of Treadmill Walking on the Strait Lines of Travel for People with Visual Impairments. Korean Journal of Adapted Physical Activity. 2006;14(2):55-72

29. Kwon OH, Woo JH, Woo YK. The Effects of task-oriented treadmill gait training on the walking ability and balance of sub-acute stroke patient. J Korean Acad Ther. 2013;5(1):13-23

30. Sackley CM, Baguley BI, Gent S et al. The use of a balance performance monitor in the treatment of weight-bearing and weight-transference problems after stroke. Physiotherapy. 1992;78(12):907-13.

31. Warren M. Evaluation and treatment of visual deficit. In: Pedretti LW,Occupational therapy practice skill for physical dysfunction, 5th ed, st Louis, Mosby. 2001.

32. Srivastava A, Taly AB, Gupta A et al. Post-stroke balance training: Role of force platform with visual feedback technique. J Neurol Sci. 2009;287:1-2:89-93.

33. Kang HK, Chung YJ. Effects of treadmill training with real optic flow scene on balance and balance self-efficacy in individuals following stroke: A pilot randomized controlled trial. Phys Ther Rehabil Sci. 2012; 1(1):33-39. 